\title{
Competitive Anxiety in Professional Soccer Players: An Interdisciplinary Work
}

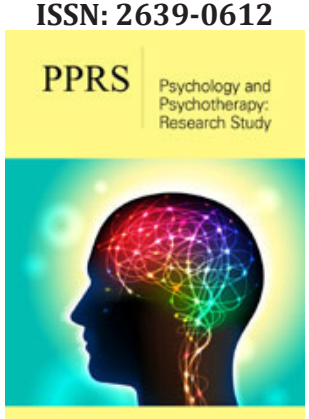

*Corresponding author: Boryi Alexander Becerra, Master's in Physical Activity, Training and Sports Management, Columbia, USA

Submission: 眥 July 22, 2019

Published: 笽 August 12, 2019

Volume 2 - Issue 4

How to cite this article: Competitive Anxiety in Professional Soccer Players: An Interdisciplinary Work. Competitive Anxiety in Professional Soccer Players: An Interdisciplinary Work. Psychol Psychother Res Stud. 2(4).PPRS.000542.2019.

DOI: 10.31031/PPRS.2019.02.000542

Copyright@ Boryi Alexander B, This article is distributed under the terms of the Creative Commons Attribution 4.0 International License, which permits unrestricted use and redistribution provided that the original author and source are credited.

\section{Boryi Alexander B*}

Training and Sports Management, USA

\section{Opinion}

This review is justified in the possibility of understanding those elements that continually converge in the so-called game cycle and interdisciplinary convergence of the field of sports psychology carried out by goals, objectives, motivation, attention, concentration and anxiety, as well as that of dep ortivo training linked to obtaining good results mediated by high yields, assertive capacity in decision-making, optimal observatory processes and creative and spontaneous responses to the demands of the game, highlighting the possibility of developing training styles [1] that can contribute interchangeably according to the moment, phase and game situation that occurs randomly in the competition. This relationship between the interdisciplinary team of sportsmen and sports psychologist must contribute to detect these negative variations and seek to deactivate feelings of suspicion and fear, so that the players contain and reformulate in each of the competitive situations the exteriorization of threatening evidence, leading to the error and alteration of their psychophysiological functions, creating an increase in activation levels, producing a positive transformation of competitive anxiety [2].

This review of the elements associated with competitive anxiety as a fundamental axis in the achievement of the objectives for the development of sports practice, leads to the imperative need to describe the factors related to anxiety as a response to the stress produced and that perceives the Unisone athlete, creating invariabilities of multifactor response of the spectrum of stimuli that periodically recreates the competition. It should be noted that this differentiation of the tria gives perception-decision-execution proliferates invariable responses in depth and space-time for some players who learn to cohabit in the dynamic, variable and intermittent game and where others are negatively influenced by the degree of activation physics they receive, finding intimidating situations [3]. The relationship in the competition of professional soccer players is influenced by the capture and differentiation in the stimuli that are received through electromagnetic waves, pressure waves, mechanical changes and chemical particles [4], creating alterations of everything that is seen, heard, touched and perceived as pleasant or dawning, this electrical information travels rapidly through axons and dendrites with final destination in the brain areas [5], to accumulate and process the information that is receives, generating perceptual-motor responses in response to the demands of the game [4].

\section{Conclusion}

In conclusion, competitive anxiety (cognitive and somatic) is continually associated with the inability to manifest naturally and continuously the enjoyment of sports activity $[6,7]$, as well as the proliferation of difficulties that arise around the Athlete who must perennially perceive, analyze, observe and make decisions. Likewise, the study by García et al. [8] reveals that cognitive anxiety is externalized more than somatic anxiety, and that the game as a random, indiscriminative and fluctuating element denotes and permeates the final decisions and executions of athletes, not meeting Indicative relationship of perception of ability and subjective performance of coaches to which athletes actually express. That 
is why the interdisciplinarity of the psychological-sports area must work together to facilitate the adaptation of athletes to the competition, allowing to relieve tensions and reduce those negative feelings, expressed from the body such as (tensions, injuries, anguish, depression, psychosis) and of the mind (deconcentrating, demotivation, low self-confidence, indecision, stress, blockages) so that each player can overcome these disadvantages and can continually enhance their performance [9] (Table 1).

Table 1: Contextual competitive anxiety in football. Adapted from: Rodriguez et al. [5].

\begin{tabular}{|c|c|c|}
\hline Type of Answers in The Competition & Anxiety Cognitive & Anxiety Somatic \\
\hline $\begin{array}{l}\text { Visualization of the objectives and goals (pre- } \\
\text { competition) }\end{array}$ & Alert & Increased tension muscular \\
\hline $\begin{array}{l}\text { Predisposition of their efforts and rituals } \\
\text { towards the start of the game (pre-competition) }\end{array}$ & Awake & Increase in Breathing frequency \\
\hline $\begin{array}{l}\text { Facial and corporeal expressions that entail to } \\
\text { manifest one-person behavior unknown (pre- } \\
\text { competition) }\end{array}$ & Fearful & Heart rate high \\
\hline Feeling of uncertainty and adaptation to game & Apprehensive & Increase in perspiration \\
\hline First execution error made. & Thoughts negatives & Muscle Relaxation Lisa \\
\hline $\begin{array}{l}\text { Mismatch of your role within the cycle of game } \\
\text { and continuous bad decisions }\end{array}$ & Dubitative in the decisions & Alteration period of latency \\
\hline
\end{tabular}

\section{References}

1. Sousa C, Smith R, Cruz J (2008) An individualized behavioural goalsetting program for coaches. Journal of Clinical Sport Psychology 2(3): 258-277.

2. Garret W, Kirkendall D, Contuiguglia SR (2005) Football medicine. Paidotribo, Spain.

3. Rodríguez M, Izquierdo JM, Ruiz JA, Mendoza A (2008) Personality diagnosis in competitive sport. Wanceulen, Soccer, Spain.

4. Izaguirre M (2017) Teaching and learning neuroprocessing. Methodology of application of neuroscience in education, Alfaomega, Bogotá, Colombia.

5. Machado S, Portella CE, Silva JG, Velasques B, Bastos VH, et al. (2008) Learning and implicit memory: mechanisms and neuroplasticity. Rev Neurol 46(9): 543-549.
6. Scanlan TK, Babkes ML, Scanlan LA (2005) Participation in sport: A developmental glimpse at emotion. In: Mahoney JL, et al. (Eds.), Lawrence Erlbaum Associates Publishers, New Jersey, USA.

7. Mahoney Joseph L, Larson RW, Eccles JS (2005) Organized activities as contexts of development: Extracurricular activities, after school, and community programs, pp. 275-309.

8. García-Mas A, Palou, Smith RE, Ponseti, Pedro Almeida, et al. (2011) Performance anxiety and motivational climate in young competitive soccer players in relation to performance and skills perceived by their coaches. Journal of Sports Psychology 20(1): 197-207.

9. Roffé M (2008) Psychology of the soccer player: with the head made ball Good ones Aires, Argentina. 